\title{
Most Preferred Market Venues for Locally Grown Fresh Produce among Online Shoppers
}

\author{
Jean D. Gumirakiza ${ }^{1} \&$ Sarah M. VanZee $^{1}$ \\ ${ }^{1}$ Department of Agriculture, Western Kentucky University, Bowling Green, KY, USA \\ Correspondence: Jean D. Gumirakiza, Department of Agriculture, Western Kentucky University, EST 237, 1906 \\ College Heights BLVD \# 410066, Bowling Green, KY 42101, USA. Tel: 1-270-363-7134. E-mail: \\ dominique.gumirakiza@wku.edu
}

$\begin{array}{lcc}\text { Received: May 29, } 2017 & \text { Accepted: July 1, } 2017 & \text { Online Published: September 15, } 2017 \\ \text { doi:10.5539/jas.v9n10p26 } & \text { URL: https://doi.org/10.5539/jas.v9n10p26 }\end{array}$

The research is financed by the USDA-NIFA.

\begin{abstract}
This paper examines the most preferred market venues online shoppers use when purchasing locally/regionally grown fresh produce. We surveyed 1,205 consumers who made online purchases at least twice within six months prior to participating in this study. We call these consumers "online shoppers". The study was conducted in the Southern region of the U.S. We collected data using Qualtrics actively managed market research panels and social media such as Facebook, and Twitter. Results indicate that grocery stores are the most preferred market venue online shoppers use to purchase locally/regionally grown fresh produce with a relative probability of 44 percent. Farmers' markets are the second most preferred market venues with a likelihood of 33 percent. The third market venue is on-farm/CSA programs with relative probability of seven percent. Online markets are currently the fourth most frequented with a likelihood of five percent. 11 percent have no particular most preferred market venue. This analysis is significant to fresh produce growers and marketers. Results suggest new marketing strategies to conveniently make fresh produce accessible among online shoppers. Furthermore, this study is useful for future studies with interests in explaining the preferred market venues for local/regional fresh produce among online shoppers.
\end{abstract}

Keywords: online shoppers, market venues, locally grown fresh produce

\section{Introduction}

Internet is shaping the way consumers shop. Online markets are fast expanding as more consumers are increasingly shopping online and businesses are solidifying their presence online. Judith (2012) posited that with the existence of mobile devices, smartphones, and tablets, online shopping has become more convenient. As Kotler and Armstrong (2012), and Rigby (2012) pointed out, nowadays web presence among consumers and organizations is becoming increasingly common. There are various market venues for locally and regionally grown fresh produce. These include farmers' markets, Community Supported Agriculture (CSA) programs, on-farm programs, grocery stores, and online markets. In its research, Neilson Company (2015) indicated that online retailers of fresh produce have tremendous opportunity to do well in the online market environment. With this fast increasing trend, local food marketers are faced with critical questions: Given that consumers are becoming "online shoppers", what are their most preferred market venues for local/regional fresh produce? Will the offline direct-to-consumer market outlets prevail? Are these online shoppers interested in purchasing fresh produce through online markets?

This paper investigates the most frequent market venues that online shoppers are currently getting local/regional fresh produce from. Specific objectives are to: (1) describe consumer characteristics that explain the preferred market venues for local/regional fresh produce among online shoppers, (2) estimate the relative likelihood for online shoppers to purchase fresh produce at a given market venue, (3) explain marginal effects that the consumer characteristics have on each specific preferred market venue for local/regional fresh produce among online shoppers. Online shopping is included in the market venues to estimate its likelihood relative to other market venues. 
To our knowledge, this study is the first to look at fresh produce market preferences among online shoppers. Most of the previous research studies directed their attention towards famers' market consumers. Examples of such studies include Conner et al. (2010), Ruelas et al. (2012), Abello et al. (2012), Gumirakiza et al. (2014), Zepeda et al. (2012), Freedman et al. (2014), Racine et al. (2013), and Kraschnewski et al. (2014). Other studies like Curtis et al. (2015), Meyer (2012), Conner et al. (2010), and Woods and Troppy (2015) focused on CSA programs. This study sets a basis for future analyses that will be interested in tracking changes in the preferred market venues for local/regional fresh produce among online shoppers. This analysis is significant to fresh produce growers for it provides information regarding most proffered market venues for their products among the increasingly common type of consumers. A successful fresh produce grower would be interested in coping with consumer trends. Likewise, agricultural marketers in the local food movement; including fresh produce retailers will find this study significant. Results will help the marketers in adopting new marketing strategies to conveniently make fresh produce accessible to online shoppers.

\section{Literature Review}

Eating locally grown fresh food is one of the popular recommendations in healthy eating and supporting community farm businesses. There are various ways to obtain locally grown food, such as farmers' markets, CSA programs, on-farm opportunities, online, and in grocery stores. All of these market venues provide consumers with fresh produce. Existing literature provides characteristics of consumers who attend these market venues. But, very little is known about consumers in the online markets.

Mirosa et al. (2012) indicated that middle-aged educated individuals are the main consumers of locally grown food. Studies by Curl et al. (2013), and Onozaka et al. (2010) got the same results and added affluent households and white females as other significant factors. A study conducted by Racine et al. (2012) shows that those who lived in rural areas were more likely to purchase locally grown food. Their study also showed that individuals who ate more than five servings of fresh produce daily were more likely to purchase locally grown foods. Feldmann et al. (2015) found that those who lived in close proximity to local food outlets were more likely to buy locally grown foods. Both studies support that many consumers visit farmers' markets out of convenience.

Farmers' markets are one of the most common ways individuals obtain locally grown food. They bring the farm into the community and provide a way for many people to obtain fresh local food. In an effort to increase diversity of consumers of farmers' markets, many markets now accept SNAP (supplemental nutrition assistance program), and senior vouchers. However, in a study that Wetherill et al. (2015) conducted in Oklahoma revealed that several individuals are unaware. Consequently, low-income individuals are reportedly not part of many farmers' market consumers (Crow et al., 2011; Murphy, 2011; Rice, 2015). Nevertheless, Ruelas et al. (2012) showed a correlation of low-income consumers shopping at farmers' markets in Los Angles.

In recent years many studies identified characteristics of families who attend farmers' markets. A study conducted by Cassia et al. (2012) discovered that the majority of farmers' market consumers are those with only two people in the household. Additional studies found that small families, those composed of two to four persons, are more likely to purchase locally grown foods from farmers' markets (Arrington et al., 2010; Gumirakiza et al., 2014; Pascucci et al., 2011). Their studies suggest that those with smaller families can affordably and conveniently provide local produce for their families at farmers' markets. This seems to contribute to the high percentage of small families that take part in farmers' market outlets.

Community Supported Agriculture (CSA) programs fit well for working families. They allow for consumers to obtain locally grown food without the hassle of growing their own. CSA programs function through annual membership fees that consumers pay to growers in advance. When the produce is ready for consumption, members pick up their share of food at the farm or at any other specified place. CSA consumers have been found to be uniform. Studies have proved that most CSA participants are affluent, middle aged women (Lang, 2010; Pole et al., 2015; Vasquez et al., 2016). Many CSA consumers view eating locally grown foods, as well as healthy foods important. It is noteworthy to mention that Okoye et al. (2014) pointed out that many CSA farm participants do not allow consumers with SNAP benefits to use them. This limits access to fresh produce among such consumers.

Studies about local fresh produce available in grocery stores have varying definitions of the word "local" based on the size of the grocery store. Dunne (2011) indicated that the bigger the store the more broad the definition of local is. Blanch et al. (2011) found that barely 27 percent of grocery store shoppers would also use farm-to-consumer market outlets at least weekly. When it comes to purchasing fresh produce from store or farm-to-consumer venues, their study found no significant differences among gender, race/ethnicity, education, and annual household income. A study by Martinez et al. (2010) concluded that older affluent females were those 
more likely to purchase locally grown foods grocery stores. There are consumers who enjoy visiting farm and/or engaging in agritourism events. Some famers offer market opportunities through roadside stands and/or U-Pick. Others organize events allowing consumers to tour farms and learn more about locally grown food. According to Govindasamy et al. (2014) those who participate in these outlets tend to be local community members that are well educated. Thorp et al. (2015) reported that those who participate in these outlets are tourists, not necessarily community members.

\section{Methodology}

\subsection{Data Collection Process}

This study uses data collected from a stratified randomly selected sample of 1,205 online shoppers. The target population of interest for this study is consumers who have made at least two online purchases of any kind within six months prior to participating in this study. Hence, they are referred to as being online shoppers. This study targeted online shoppers that reside within the Southern region of the U.S. The states that are in this region are: Arkansas, Delaware, Florida, Georgia, Kentucky, Louisiana, Maryland, Mississippi, North Carolina, Oklahoma, South Carolina, Tennessee, Texas, Virginia, West Virginia, and the District of Columbia (U.S. Census Bureau, 2016).

In this study, we used the Qualtrics software to create the survey. The software has integrated capabilities to make possible the accurate tracking, profiling, monitoring of responses for each respondent. It also allowed us to use the design survey questions using advanced branching logic, randomization, question block presentation, and question timing. The benefit from these features was to avoid possible bias that could arise during survey taking. To ensure that respondents are in fact paying attention to each question included in the survey, we added questions requiring respondents to think and provide a correct answer. Those who gave incorrect answers were automatically excluded from the survey.

The data were collected between March and July, 2016. The survey was emailed to respondents that were randomly selected from online shoppers within the Qualtrics actively managed market research panels and to those using social media such as Facebook, and Twitter. Qualtrics is a professional survey software provider that offers sophisticated and advanced online data collection tools combined with respondent panels. Qualtrics partners with over 20 online panel providers to supply a network of diverse and quality respondents to meet specific sample requirements. To ensure quality and data validity, every IP (Internet Protocol) address/location was checked and a sophisticated digital fingerprinting technology was used.

The survey questions that are relevant to this study include six market alternatives for local/regional fresh produce and consumer characteristics. The former is used as a dependent variable while the later are explanatory variables. The six market alternatives were: farmers' markets, CSA programs, on-farm, online markets, grocery stores, and the "none" option. Note on the "grocery store" alternative: respondents were told to check this option only if they read labels before buying to make sure the produce is fresh and grown locally (within state boundaries) or regionally (within a 400 mile-radius from respondent's location). We found that only 1 percent of the online shoppers use CSA programs as the most frequent when purchasing local/regional fresh produce. For this reason, CSA and on-farm were combined together. Consequently, the dependent variable consists of four market alternatives: farmers' markets, on-farm/CSA programs, online markets, grocery stores, and the "none" (no preferred market venue) option.

\subsection{Model Specification}

In order to estimate the relative probabilities of choosing a particular market alternative to be the most frequent, a multinomial logistic model is appropriate. Chan (2005) indicated that the structure of this model allows predicting the probability that the $j^{\text {th }}$ alternative in a set of more than two alternatives is chosen. Chan also posited that this model is appropriate when a systematic utility is modeled in terms of characteristics of respondents. He further urged that this model is applied when examining relative probabilities of alternatives that are provided in an unordered way.

This analysis relies on three main assumptions. First, online shoppers are rational. This means that they strive to maximize utility/satisfaction and that their preferences are both complete and transitive (Mas-Colell et al., 1995). Second, the Independence from Irrelevant Alternatives (IIA) holds true. This means that adding a new market alternative to the set of alternatives does not affect the relative odds among the existing choice set (Train, 2009). Finally, we assume that a consumer with a finite set of choice alternatives will select the one that he/she believes gives him/her the maximum amount of utility. A consumer's utility derived from a choice set is specified as a linear function of the consumer's characteristics, along with an error term. The situation is that an individual 
online shopper $i$ is presented $\mathrm{J}$ alternatives and is assumed to choose one he/she believes provides the highest utility. The utility function takes the form,

$$
U_{i j}=V_{i j}+\varepsilon_{i j}, \text { for } i=1, \ldots, I \text { and } j=1, \ldots, J
$$

Where, $V_{i j}$ is the deterministic component of the utility and $\varepsilon_{i j}$ is the random component.

We assume that the random component term is independently and identically distributed (iid) according to an extreme value $F\left(\varepsilon_{i j}\right)=\exp \left(-\exp \left(-\varepsilon_{i j}\right)\right)$ so that logistic model becomes appropriate (Kennedy, 2008). As in Onozaka and Thilmany-McFadden (2011), we assume a linear-in-parameter utility functional form for the deterministic component of utility.

The choice of one of the $J$ unordered market alternatives is driven by a latent variable or indirect utility. The indirect utility $V_{i j}{ }^{*}$ for individual $i$ choosing an alternative $j$ is,

$$
V_{i j}^{*}=\beta^{\prime} X_{i j}+\mu_{i j} \text {, for } i=1, \ldots, I \text { and } j=1, \ldots, J
$$

Where, $X_{i j}$ is a vector of characteristics of the chooser. The parameter $\beta$ is to be estimated and differs across alternatives. The $\mu_{i j}$ is the disturbance that account for unobserved factors. As researchers, we do not observe individual's utility. Instead, we observe the choices that make implying that they choose an alternative that maximizes their utility. The observed choice $y_{i}$ of an individual $i$ is,

$$
\left[y_{i}=1 \Leftrightarrow \mathrm{V}_{i 1}^{*}>V_{i j}^{*} \forall j, y_{i}=2 \Leftrightarrow \mathrm{V}_{i 2}^{*}>V_{i j}^{*} \forall j, \ldots, y_{i}=J \Leftrightarrow \mathrm{V}_{i J}^{*}>V_{i j}^{*} \forall j\right]
$$

The probability $(P)$ that an individual $i$ chooses alternative $j$ is expressed as:

$$
P_{i j}=P\left(y_{i}=j\right)=\frac{\exp \left(\beta_{k}^{\prime} X_{i j}\right)}{\sum_{j} \beta_{k}^{\prime} X_{i j}}
$$

The $\beta$ 's are identified by setting the $\beta_{j^{*}}=0$ for one reference alternative; $j^{*}$. The "None" option is the reference category in this analysis. From Equation (4), we generate a direct interpretation of the parameter estimates as follows:

$$
\frac{\delta \log \left(P_{j} \mid P_{j^{*}}\right)}{\delta X_{k}}=\beta_{i k}-\beta_{j^{*}}
$$

which reduces to,

$$
\frac{\delta \log \left(P_{j} \mid P_{j^{*}}\right)}{\delta X_{k}}=\beta_{i k}
$$

in comparison with the reference outcome $j^{*}$. According to Schmidheiny (2007), a positive parameter $\beta_{j k}$ for a continuous variable means that the relative probability of choosing $j$ increases relative to the probability of choosing the reference alternative $j^{*}$. Dummy variable effects are measured and interpreted as the probability difference between $X_{i j}$ values of zero and one. The marginal effect of an independent variable $X_{k}$ on the choice probability for an alternative $j$ is given by,

$$
\frac{\delta P(y=j \mid X)}{\delta x_{k}}=P\left(\beta_{j k}-\bar{\beta}_{j k}\right)=P\left(\beta_{j k}-\frac{\sum_{j} \beta_{j k}}{J}\right)
$$

The null hypothesis is that each independent variable has no impact on the relative probability of choosing farmers' markets, on-farm, online markets, and grocery stores as the most preferred market venue for purchasing local/regional fresh produce. That is $H_{0} \equiv \beta_{k j}=0 ; \forall k=1, \ldots, K ; j=1, \ldots, J$ for $K$ explanatories and $J$ market alternatives. The alternative hypothesis is that each independent variable has a significant impact on the relative probability of choosing farmers' markets, on-farm, online markets, and grocery store as the most preferred market venue for purchasing local/regional fresh produce. That is; $H_{1} \equiv \beta_{k j} \neq 0 ; \forall k=1, \ldots, K ; j=1, \ldots, J$ for $K$ explanatories and $J$ market alternatives.

\section{Presentation and Discussion of Results}

\subsection{Descriptive Statistics of Independent Variables}

Thirteen consumer characteristics are included in this analysis. Table 1 shows mean values associated with each of the characteristics. Conveniently, we displayed the statistics per each of the five categories of the dependent variable. This was accomplished by running the following Stata command: tabstat Age Urban Female Married Locavore Education GovAssistance FMSpendperVisit InterestLevelLocalFP MonthlySpendFreshProduce, by(Markets) stat(mean) nototal $\mathrm{f}(\% 9.2 \mathrm{f})$. "Locavore" is a dummy variable that represents those shoppers who eat more fruits and vegetables regularly believing that they help address their dietary concerns. "GovAssistance" is 
another dummy variable representing respondents who participate in either food stamps, WIC, and/or senior nutrition assistance programs. The "FMSpendperVisit" represents the amount of money respondents spend or would spend per one visit at a farmers' market. The "InterestLevelLocalFP" represents a 5-likert scale of levels of interests respondents have in locally grown fresh produce. Lastly, the "MonthlySpendFreshProduce" represents the average amount of money respondents spend on fresh produce per month. These independent variables are included in the model because we believe they reflect major consumer characteristics that are relevant and important in explaining the primary preferences. These variables are also a result of a model specification we conducted to ensure we use variables that are adequately able to make the overall model significant. Those that were insignificant across the five outcome responses were removed from the model.

Table 1. Consumer characteristics by market venues for local fresh produce

\begin{tabular}{lllllll}
\hline Markets & Farmers' Markets & OnFarm/CSA & Online Markets & Grocery Stores & None & Total \\
\hline Age & 47 & 51 & 35 & 47 & 49 & 47 \\
Urban & 0.73 & 0.57 & 0.88 & 0.8 & 0.73 & 0.76 \\
Female & 0.59 & 0.63 & 0.49 & 0.64 & 0.61 & 0.62 \\
Married & 0.59 & 0.61 & 0.59 & 0.54 & 0.49 & 0.56 \\
Locavore & 0.79 & 0.83 & 0.75 & 0.75 & 0.39 & 0.72 \\
Education & 3.40 & 3.10 & 3.54 & 3.42 & 3.13 & 3.36 \\
GovAssistance & 0.10 & 0.18 & 0.30 & 0.16 & 0.19 & 0.15 \\
FMSpen t & 40.28 & 38.95 & 78.85 & 38.56 & 15.57 & 38.39 \\
Inte $\sim$ lFP & 4.12 & 4.18 & 3.98 & 3.92 & 2.80 & 3.87 \\
Monthl e & 62.09 & 56.8 & 119.9 & 60.44 & 15.28 & 57.81 \\
Total & 412 & 84 & 49 & 530 & 130 & 1205 \\
\hline
\end{tabular}

Overall, these statistics indicate that an average online shopper is 47 years old, completed a 2-year associate's degree, and is interested in attending farmers' markets. This average shopper would spend $\$ 38.39$ at a farmers' market per one visit and spends $\$ 57.81$ on locally/regionally grown fresh produce per month. Among those who participated in this study, 76 percent live in areas they consider to be urban, 62 percent are females, 56 percent are married, 72 percent are locavores, and 15 percent are recipients of some form of food assistance. Statistics about each market venue are available in Table 1. For example, an average online shopper whose most preferred market venue for local/regional fresh produce is farmers' market is 47 years old, completed a 2-year associate's degree, and is interested in attending farmers' markets. He/she would spend $\$ 40.28$ at a farmers' market per one visit; a little bit more than what an overall average online shopper would spend. This shopper spends an average of $\$ 62.09$ on locally/regionally grown fresh produce per month. Among these farmers' market funs, 73 percent live in areas they consider to be urban, 59 percent are females, 59 percent are married, 79 percent are locavores, and 10 percent are recipients of some form of food assistance. We found that individuals who are in mid-fifties favor online markets while those in fifties like getting their fresh produce through on-farm/CSA programs. This indicates that those who are younger and more experienced using newer technology are the individuals are more likely to purchase fresh, local produce from the online markets.

\subsection{Regression Results}

The dependent variable for the multinomial logistic model regression consists of five discrete categories. These categories are the four market venues for locally grown fresh produce: (1) Farmers' markets, (2) On-farm and CSA programs, (3) Online markets, (4) grocery stores, and (5) the "none" option. Results in Table 2 are coefficient estimates computed using the following Stata command: mlogit PrimaryMarketLocalProduce Age Urban Female Married Locavore Education GovAssistance FMSpendperVisit InterestLevelLocalFP MonthlySpendFreshProduce, base (None). 
Table 2. Coefficient Estimates from the Multinomial Logistic Model

\begin{tabular}{|c|c|c|c|c|}
\hline Variable & Farmers' Markets & On-Farm/CSAs & Online Markets & Grocery Stores \\
\hline Age & -0.001 & $0.038^{* * *}$ & $-0.044^{* * *}$ & 0.003 \\
\hline Urban & $-0.230^{*}$ & $-0.673^{* *}$ & 0.311 & $0.125^{* *}$ \\
\hline Female & $-0.188^{* *}$ & -0.029 & -0.541 & $0.167^{* * *}$ \\
\hline Married & -0.127 & -0.153 & 0.170 & $0.263^{*}$ \\
\hline Locavore & $1.101^{* * *}$ & $1.299^{* * *}$ & $0.822 *$ & $0.906^{* * *}$ \\
\hline Education & 0.104 & $-0.151^{* *}$ & 0.108 & 0.126 \\
\hline GovAssistance & $0.692^{* *}$ & -0.110 & -0.249 & 0.286 \\
\hline FMSpendperVisit & $0.025^{* * *}$ & $0.026^{* * *}$ & 0.033 & $0.025^{* * *}$ \\
\hline InterestLevelLocalFP & $0.775^{* * *}$ & $0.990^{* * *}$ & $0.568^{* * *}$ & $0.585^{* * *}$ \\
\hline MonthlySpentFreshProduce & $0.028^{* * *}$ & $0.160^{* *}$ & $0.020^{* * *}$ & $0.064^{* * *}$ \\
\hline Constant & $-4.121^{* * *}$ & $-7.234^{* * *}$ & $-3.210^{* *}$ & $-3.046^{* * *}$ \\
\hline \multicolumn{5}{|l|}{ Stats: } \\
\hline Prob $>$ chi $2=$ & 0.00 & & & \\
\hline Pseudo R2 = & 0.1328 & & & \\
\hline $\log \mathrm{L}=$ likelihood $=$ & -1187.349 & & & \\
\hline Observations $=$ & 1205 & & & \\
\hline
\end{tabular}

Note. The $*{ }^{* *}$, and $* * *$ denote significance at the $10 \%, 5 \%$, and $1 \%$ level, respectively.

The MNL model above compares the four major market outlets where people can purchase fresh, local produce. None is the reference category. Thus, the coefficient estimates in the MNL model (Table 2) are interpreted in comparison to this reference category (no preferred market venue). A positive coefficient estimate shows that an increase in the variable is associated with an increase in the relative probability of the corresponding outcome. Specifically, age has a positive significant effect on the likelihood of favoring the on-farm/CSA markets, but an inverse effect on the likelihood for the online markets. Compared to rural residents, urban respondents are less likely to favor farmers' markets and on-farm/CSA programs, but more likely to favor grocery stores. Likewise, online shopper females are less likely to opt for farmers' markets, but more likely to prefer grocery stores. Married online shoppers show significant preferences for grocery stores. Interestingly, locavores significantly prefer all four venues. Results for other variables are presented in Table 2 above.

The relative probabilities and marginal effects for each of the market venues are shown in Table 3 . The marginal effects were computed using the following Stata command: mlogit PrimaryMarketLocalProduce Age Urban Female Married Locavore Education GovAssistance FMSpendperVisit InterestLevelLocalFP MonthlySpendFreshProduce. Then a post-estimate command: margins, $\operatorname{dydx}\left({ }^{*}\right)$ for each of the five outcomes was applied to estimate marginal effect of variables in varlist. In other words, we used the following: margins, $\operatorname{dydx}\left({ }^{*}\right) \operatorname{predict}(\operatorname{outcome}(1))$, margins, $\operatorname{dydx}\left({ }^{*}\right) \operatorname{predict}(\operatorname{outcome}(2))$, margins, $\operatorname{dydx}\left({ }^{*}\right) \operatorname{predict}($ outcome(3)), margins, $\operatorname{dydx}(*)$ predict(outcome $(4))$, margins, $\operatorname{dydx}(*)$ predict(outcome $(5))$.

Table 3. The Marginal Effects from the Multinomial Logistic Model

\begin{tabular}{|c|c|c|c|c|c|}
\hline Variable & $\begin{array}{l}\text { Farmers Markets }=\mathbf{3 3} \% \\
\mathrm{dy} / \mathrm{dx}\end{array}$ & $\begin{array}{l}\text { On-Farm } / \text { CSA's }=\mathbf{0 7 \%} \\
\mathrm{dy} / \mathrm{dx}\end{array}$ & $\begin{array}{l}\text { Online Market }=\mathbf{0 5} \% \\
\mathrm{dy} / \mathrm{dx}\end{array}$ & $\begin{array}{l}\text { Grocery Stores }=\mathbf{4 4 \%} \\
\mathrm{dy} / \mathrm{dx}\end{array}$ & $\begin{array}{l}\text { None }=11 \% \\
\text { dy } / d x\end{array}$ \\
\hline Age & -0.00048 & $0.0021^{* *}$ & $-0.0018^{* * *}$ & 0.0003 & 0.0006 \\
\hline Urban & $-0.0515^{*}$ & $-0.0389^{* *}$ & 0.0161 & $0.0704^{* *}$ & 0.0039 \\
\hline Female & $-0.0691^{* *}$ & -0.0047 & -0.021 & $0.081^{* * *}$ & -0.0002 \\
\hline Married & 0.0227 & 0.0150 & 0.0144 & $0.0402^{*}$ & 0.0128 \\
\hline Locavore & $0.0509^{* * *}$ & $0.0191^{* * *}$ & 0.0144 & $0.0318^{* * *}$ & $-0.077^{* * *}$ \\
\hline Education & 0.0012 & $-0.0130 * *$ & 0.0009 & 0.0178 & -0.0085 \\
\hline GovAssistance & $0.1032^{* *}$ & -0.0223 & $-0.0242 *$ & -0.0257 & -0.0310 \\
\hline FMSpendperVisit & $0.0357^{* * *}$ & $0.0170^{* * *}$ & $0.0197 *$ & $-0.0072^{* * *}$ & $0.0021^{* * *}$ \\
\hline InterestLevelLocalFP & $0.05137^{* *}$ & $0.0189_{* *}$ & $0.026^{* * *}$ & $-0.0398 * *$ & $0.0528^{* * *}$ \\
\hline MonthlySpentFreshProduce & $0.0312^{* * *}$ & $0.0581^{* * *}$ & $0.00019^{* * *}$ & $0.01^{* * *}$ & $0.0015^{* * *}$ \\
\hline
\end{tabular}

Note. The $*, * *, * * *$ denote significance at the $10 \%, 5 \%$, and $1 \%$ level, respectively. 
The relative probability that a consumer shops for fresh local produce at a farmers' market is 33 percent. There is almost 11 percent likelihood that those online shoppers who receive any type of food-related government assistance would be more likely to prefer purchasing locally grown fresh produce at farmers' markets. This can be attributed to the fact that there are some incentives to attract those consumers on the food-related government assistance at farmers' markets. We furthermore report a five percent increase in the probability that someone would shop at a farmers' market if they had an interest in local food. There are many programs, such as Kentucky Proud, which try to increase consumer knowledge and concern about locally grown fresh produce. There is a seven percent fall in probability of shopping at farmers' markets for females. Locavore are five percent more like to favor farmers' markets as their primary venue for local fresh produce. On the other hand, this study found that females are less likely to shop for fresh local produce at farmers' markets. Likewise, those in urban areas are seven percent less likely to purchase fresh, local food from farmers' markets. Those who live in rural areas are more likely to purchase local food from farmers' markets.

The relative probability that a consumer shops for fresh local produce on a farm or through a CSA is seven percent. Ten more years old leads to two percent more likely to participate in on farm/CSA programs to obtain fresh, local produce. There is also an increased likelihood that someone participating in on farm outlets or CSA programs has an interest in local food products by two percent. Those who are interested in local food normally seek out ways to obtain it. Those who live in urban areas are four percent less likely to shop on farms or through CSA programs than their rural counter parts. Additional level of education also decreases the probability of shopping on farms or through CSA program by one percent.

The relative probability that a consumer shops for fresh local produce through an online market is five percent. The interest in local fresh produce has a significant positive influence on the preference to purchase produce from the online markets. One level of interest increases the likelihood of purchasing through the online markets by almost three percent. Interestingly enough, we found that those online shoppers, who receive some sort of food-related government assistance, are two percent more likely to consider online marketplace as their primary market venue for local/regional fresh produce. We further found that $\$ 1,000$ additional annual income translates into a 20 percent likelihood to prefer to primary purchase fresh produce online. This suggests that as people's income increases, it is a good news to online retailers in the local fresh produce industry. Another variable with some effect is age. An increase in age decreases the likelihood of shopping online for fresh produce by roughly 0.2 percent. Likewise, females are less likely to primarily view the online marketplace as their primary market venue for local/regional fresh produce. In fact, a female is two percent less likely to do so.

The relative probability that a consumer shops for fresh local produce at a grocery store is 44 percent. This result indicates that grocery stores are the most frequent venues online shoppers use to purchase locally/regionally grown fresh produce. In this study married females have an increased likelihood to shop for local fresh produce in grocery stores. Females are eight percent more likely to shop at grocery stores for local fresh produce while married shoppers are four percent more likely to do so. Living in urban area increases the likelihood of shopping for local/regional fresh produce at grocery stores by seven percent. Another increase in probability is with the amount spending on produce each month. One dollar an individual spends on produce leads to one percent more likelihood to shop at grocery stores. Finally there is a negative effect concerning the interest level in fresh produce. With an interest in fresh, local produce there is a four percent decrease in the probability that an individual will shop for fresh, local produce at a grocery store. The relative probability that an online shopper has no preferred market when purchasing fresh produce is 11 percent.

\section{Conclusion}

Online shopping has gained great popularity in today's society. It is only logical that people are starting to buy their food online. Having an outlet to buy fresh, local produce without having to leave the house and avoiding the crowds is a huge benefit for many consumers. In this study, we examined the most preferred market venues that online shoppers use when purchasing locally/regionally grown fresh produce. We targeted consumers who made at least any two online purchases within six months prior to participating in this study (herein referred to as "online shoppers"). We randomly selected 1,205 online shoppers residing within the Southern region of the U.S participated in this study. We collected data using Qualtrics actively managed market research panels and social media such as Facebook, and Twitter.

Key results indicate that grocery stores are the most preferred market venue online shoppers use to purchase locally/regionally grown fresh produce. The relative probability associated with this situation is 44 percent. Farmers' markets are the second most frequent market venues with a relative likelihood of 33 percent. The third market venue is on-farm (road stands, you-pick-your own, and agritourism) and CSA programs with a relative 
probability of 7 percent. Online market is currently the fourth most frequent with a relative likelihood of 5 percent. 11 percent of the online shoppers have no particular market venue they consider as primary.

Adoption of online shopping for locally/regionally fresh produce is still low. When compared to pace of shopping online for other items, this is concerning. Local food growers and/or marketers should find ways to make shopping online for fresh, local produce a success. We also suggest that further studies aiming at explaining reasons behind this be conducted. Marketing strategies by those who promote farmers' markets should target online shoppers. Grocery stores should do likewise. Growers of local/regional fresh produce are encouraged to revise their marking strategies based on the consumer characteristics that are found to increase the likelihood of preferring their specific market venue. Finally, we encourage future research studies to explain clearly reasons why few consumers are participating in online markets for locally grown fresh produce.

\section{References}

Abello, F. J., Palma, M. A., Anderson, D. P., \& Waller, M. W. (2014). Evaluating the factors influencing the number of visits to farmers' markets. Journal of Food Products Marketing, 20, 17-35. http://dx.doi.org/ $10.1080 / 10454446.2013 .807406$

Arrington, K., Dennis, J. H., Ayres, J., \& Dooley, F. (2010). An Evaluation of Consumer Segments for Farmers' Markets in Indiana and Illinois. ProQuest Dissertations and Theses.

Blanck, H. M., Thompson, O. M., Nebeling, L., \& Yaroch, A. L. (2011). Improving Fruit and Vegetable Consumption: Use of Farm-To-Consumer Venues among U.S. Adults. Prev Chronic Dis, 8(2).

Chan, Y. H. (2005). Biostatistics 305. Multinomial Logit Regression. CME Article. Retrieved from http://www.nuhs.edu.sg/wbn/slot/u3344/biostats305_multinomial.pdf

Conner, D., Colasanti, K., Ross, R. B., \& Smalley, S. B. (2010). Locally Grown Foods and Farmers' markets: Consumer Attitudes and Behaviors. Sustainability, 3(2), 742-756. https://doi.org/10.3390/su2030742

Crow, C., Henneberry, S. R., Norwood, B., \& Shideler, D. (2011). Improving Consumer Participation in Local Food Markets: A Case Study of Oklahoma Farmers' Markets. ProQuest Dissertations and Theses.

Curl, C. L., Beresford, S., Hajat, A., Kaufman, J., Moore, K., Nettleton, J. A., \& Diez-Roux, A. (2013). Associations of organic produce consumption with socioeconomic status and the local food environment: Multi-Ethnic Study of Atherosclerosis (MESA). PloS One, 8(7), e69778. https://doi.org/10.1371/journal. pone.0069778

Curtis, K., Ward, R., Allen, K., \& Slocumd, S. (2015). Impacts of Community Supported Agriculture Program Participation on Consumer Food Purchases and Dietary Choice. Journal of Food Distribution Research, 44(1), 42-51. Retrieved from http://ageconsearch.umn.edu/bitstream/158780/2/AgProgramParticipation.pdf

Dunne, J. B., Chambers, K. J., Giombolini, K. J., \& Schlegel, S. A. (2011). What Does 'Local' Mean in the Grocery Store? Multiplicity in Food Retailers' Perspectives on Sourcing and Marketing Local Foods. Renewable Agriculture and Food Systems, 36(1), 46-59. https://doi.org/10.1017/S1742170510000402

Fabio, C., Marta, U., Angelo, B., \& Claudia, C. (2012). The Perceptions of Italian Farmers' Market Shoppers and Strategic Directions for Customer-Company-Territory Interaction (CCTI). Procedia-Social and Behavioral Sciences, 58, 1008-1017. https://doi.org/10.1016/j.sbspro.2012.09.1081

Feldmann, C., \& Hamm, U. (2015). Consumers' Perceptions and Preferences for Local Food: A Review. Food Quality and Preference, 40, 152-164. https://doi.org/10.1016/j.foodqual.2014.09.014

Freedman, D. A., Mattison-Faye, A., Alia, K., Guest, M. A., \& Hébert, J. R. (2014). Comparing Farmers' Market Revenue Trends Before and after the Implementation of a Monetary Incentive for Recipients of Food Assistance. Prev Chronic Dis, 11, E87. https://doi.org/10.5888/pcd11.130347

Govindasamy, R., \& Kelley, K. (2014). Agritourism consumers' participation in wine tasting events. International Journal of Wine Business Research, 26(2), 120-138. https://doi.org/10.1108/IJWBR-04-2013-0011

Gumirakiza, J. D., Curtis, R. K., \& Bosworth, R. (2014). Who Attends Farmers' Markets and Why? Understanding Consumer and their Motivations. International Food and Agribusiness Management Review, 17(2), 65-82. Retrieved from https://www.ifama.org/resources/Documents/v17i2/Gumirakiza-Curtis-Bosworth.pdf

Judith, A. (2012). Tablets and smartphones transform the in-store customer experience. CRM Magazine, 16(1).

Kennedy, P. (2008). A Guide to Econometrics (6th ed.). Malden, Massachusetts: Blackwell Publishing.

Kotler, P., \& Armstrong, G. (2010). Principles of Marketing (13th ed.). New Jersey: Pearson Education. 
Kraschnewski, J. L., George, D. R., Rovniak, L. S., Monroe, D. L., Fiordalis, E., \& Bates, E. (2014). Characterizing Customers at Medical Center Farmers' Markets. J Community Health, 39(4), 727-731. https://doi.org/10.1007/s10900-014-9818-x

Lang, K. B. (2010). The Changing Face of Community-Supported Agriculture. Culture, Agriculture, Food, \& Environment, 32(1), 17-26. https://doi.org/10.1111/j.1556-486X.2010.01032.x

Martinez, S., Hand, M., DaPra, M., Pollack, S., Ralston, K., Smith, T., \& Newman, C. (2010). Local food systems: Concepts, impacts, and issues (pp. 29-30). USDA. Retrieved from https://www.ers.usda.gov/publications/ pubdetails/?pubid $=46395$

Mas-Colell, A., Whinston, M. D., \& Green, J. R. (1995). Microeconomic Theory. New York: Oxford University Press.

Meyer, J. (2012). Community Supported Agriculture: A Strategic Analysis of the Market and a Competency-based Strategic Plan. A Thesis at Michigan State University. Retrieved from http://ageconsearch.umn.edu/ handle/140519

Mirosa, M., \& Lawson, R. (2012). Revealing the lifestyles of local food consumers. British Food Journal, 114(6), 816-825. https://doi.org/10.1108/00070701211234345

Murphy, A. J. (2011). Farmers' markets as retail spaces. International Journal of Retail \& Distribution Management, 39(8), 582-597. https://doi.org/10.1108/09590551111148668

Neilson Company. (2015). The future of grocery. E-commerce, digital technology, and changing shopping preferences around the world. Retrieved from http://www.nielsen.com/content/dam/nielsenglobal/vn/docs/ Reports/2015/

Okoye, R., Agyeman, J., \& Joseph, H. (2014). Cultural Recognition and Food Programming: The Cultural Inclusivity of Community Supported Agriculture in Urban, Low-Income, African American Communities. ProQuest Dissertations and Theses.

Onozaka, Y., \& Thilmany-McFadden, D. (2011). Does Local Labeling Complement or Compete with Other Sustainable Labels? A Conjoint Analysis of Direct and Joint Values for Fresh Produce Claims. American Journal of Agricultural Economics, 93(3), 693-706. https://doi.org/10.1093/ajae/aar005

Onozaka, Y., Nurse, G., \& McFadden, D. T. (2010). Local Food Consumers: How Motivations and Perceptions Translate to Buying Behavior. The Magazine of Food, Farm and Resource Issues, 25(1). Retrieved from http://www.choicesmagazine.org/magazine/article.php?article=109

Pascucci, S., Cicatiello, C., Franco, S., Pancino, B., Marinov, D., \& Davide, M. (2011). Back to the Future? Understanding Change in Food Habits of Farmers' Market Customers. International Food and Agribusiness Management Review, 14(4), 105-126.

Pole, A., \& Kumar, A. (2015). Segmenting CSA members by motivation: Anything but two peas in a pod. British Food Journal, 117(5), 1488-1505. https://doi.org/10.1108/BFJ-12-2014-0405

Racine, E. F., Mumford, E. A., \& Laditka, S. B. (2013). Understanding Characteristics of Families Who Buy Local Produce. Journal of Nutrition Education and Behavior, 45(1), 30-38. https://doi.org/10.1016/j.jneb. 2012.04.011

Rice, J. S. (2015). Privilege and exclusion at the farmers' market: Findings from a survey of shoppers. Agriculture and Human Values, 32(1), 21-29. https://doi.org/10.1007/s10460-014-9513-7

Ruelas, V., Iverson, E., Kiekel, P., \& Peters, A. (2012). The Role of Farmers' Markets in Two Low Income, Urban Communities. J Community Health, 37(3), 554-562. https://doi.org/10.1007/s10900-011-9479-y

Schmidheiny, K. (2007). Multinomial choice (basic models). Retrieved from http://kurt.schmidheiny.name/ teaching/multinomialchoice2up.pdf

Thorp, Z. W., Warf, B. B., Slocum, T., \& Brown, J. C. (2015). Agritourism in Kansas: Effects of Distance and Economic Outcomes. ProQuest Dissertations and Theses.

Train, K. E. (2009). Discrite Choice Methods with Simulation (2nd ed.). New York: Cambridge University Press. https://doi.org/10.1017/CBO9780511805271

U.S. Census Bureau. (2016). Census Regions and Divisions of the United States. Retrieved from http://www2.census.gov/geo/pdfs/maps-data/maps/reference/us_regdiv.pdf 
Vasquez, A., Sherwood, N. E., Larson, N., \& Story, N. (2016). A Novel Dietary Improvement Strategy: Examining the Potential Impact of Community Supported Agriculture Membership. Public Health Nutrition, 19(14), 2618-2628. https://doi.org/10.1017/S1368980015003638

Wetherill, M., \& Gray, K. (2015). Farmers' Markets and the Local Food Environment: Identifying Perceived Accessibility Barriers for SNAP Consumers Receiving Temporary Assistance for Needy Families (TANF) in an Urban Oklahoma Community. Journal of Nutrition Education and Behavior, 47(2), 127-133. https://doi.org/10.1016/j.jneb.2014.12.008

Woods, T. A., \& Troppy, D. (2015). CSAs and the Battle for the Local Food Dollar. Journal of Food Distribution Research, 46(2), 17-29. Retrieved from https:/www.fdrsinc.org/wp-content/uploads/2015/10/2-113-TimWoods.pdf

Zepeda, L., \& Nie, C. (2012). What Are the Odds of Being an Organic or Local Food Shopper? Multivariate Analysis of US Food Shopper Lifestyle Segments. Agriculture and Human Values, 29(4), 467-480. https://doi.org/10.1007/s10460-012-9364-z

\section{Copyrights}

Copyright for this article is retained by the author(s), with first publication rights granted to the journal.

This is an open-access article distributed under the terms and conditions of the Creative Commons Attribution license (http://creativecommons.org/licenses/by/4.0/). 